\section{Clinical, radiological and pathological examination of periocular dermoid cysts: evidence of inflammation from an early age}

Y Abou-Rayyah, GE Rose, H Konrad, SJ Chawla and IF Moseley

\begin{abstract}
Introduction Periocular dermoid cysts are common and leakage of the lipid or keratin contents leads to an inflammation-often asymptomatic-around the cyst, which may cause adherence of the dermoid cyst to neighbouring structures.

Purpose To investigate the frequency of clinical and radiological signs of inflammation with periocular dermoid cysts, to relate this to the histopathological examination of the excised specimens, and to assess whether the degree of inflammation is related to age at presentation.

Patients and Methods A retrospective noncomparative series of $\mathbf{1 2 4}$ patients with periocular dermoid cysts that had undergone imaging. Case-notes were reviewed for clinical and histopathological details and there was independent review of the radiological imaging.

Results Surgery was undertaken at between 1 and 66 years of age, most patients being under 10 years, and the duration of symptoms varied from 4 weeks to 30 years. Symptoms of inflammation-mainly intermittent lid swelling with localised redness and pain-occurred in all age groups, the proportion being greatest in the fourth decade. Clinical signs of inflammation at the time of clinic visit were relatively few, although $8 \%$ had some localised erythema and $7 \%$ had tenderness at the site of lesion.

In more than two-thirds of the excised cysts, pathological examination demonstrated various degrees of chronic inflammation, even in those cysts removed before the age of 5 years.

Conclusion Even if the patient does not
\end{abstract}

have symptoms or signs of inflammation, most periocular dermoid cysts show histological evidence of inflammation due to leakage of the lipid and keratin contents from the cyst, the incidence being similar at all ages.

Eye (2002) 16, 507-512. doi:10.1038/

sj.eye. 6700045

Keywords: dermoid cyst; orbit; presentation; radiology; pathology

Dermoid cysts are developmental choristomas (an abnormal arrangement of tissues not normally present at the site) and are often evident soon after birth, because of parental concern about a periocular lump, or an asymmetry of the eyelids or brows. More rarely the cyst may be asymptomatic until it presents with apparent enlargement or with inflammatory symptoms-such as pain, redness and eyelid swelling. ${ }^{1-3}$ Dermoid cysts are generally the commonest periorbital mass presenting in childhood ${ }^{2,4}$ and are thought to arise, at between 3 and 5 weeks gestation, ${ }^{1}$ from an abnormal implantation of surface ectoderm along the embryonic lines of closure that form the facial features. ${ }^{5,6}$ In the periorbital area, dermoid cysts are typically located near the zygomatico-frontal and fronto-ethmoidal sutures, sites of particularly complex embryology. ${ }^{7}$

The lipid and keratin content of dermoid cysts typically induces a marked inflammation in the cyst wall and secondary fibrosis may complicate surgical excision, both with difficulty in defining the plane of excision and with adhesion and damage to otherwise healthy
Moorfields Eye Hospital London EC1V 2PD, UK

Correspondence: GE Rose, MS, FRCS Orbital Clinic Moorfields Eye Hospital City Road London EC1V 2PD, UK Tel: 02072533411 E-mail: geoff.rose@ moorfields.nhs.uk

Received: 30 October 2000 Accepted in revised form: 13 August 2001 

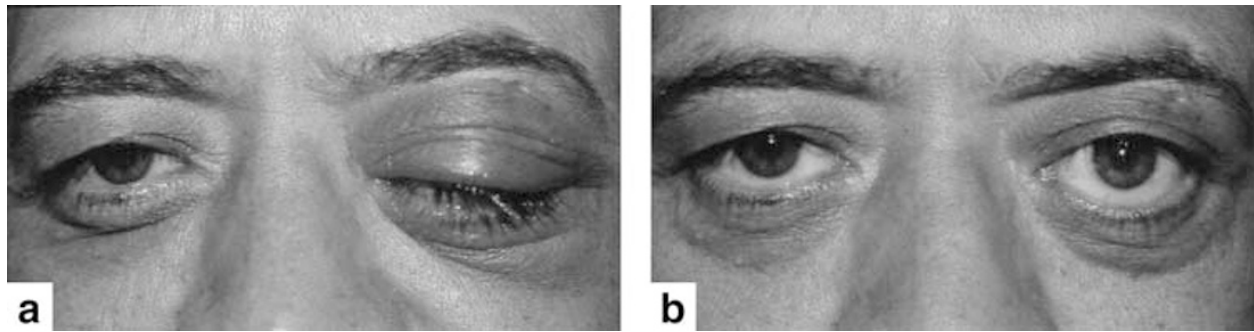

Figure 1 Severe sterile orbital cellulitis due to a leaking dermoid lying alongside the lacrimal gland, before (a) and after (b) treatment with a non-steroidal anti-inflammatory drug.

neighbouring structures. Although a patient will present only rarely with a severe, but sterile, orbital cellulitis due to an underlying leaking dermoid cyst (Figure 1), we had noted that histopathological evidence of inflammation was present in most lesions, even in childhood.

We present the symptoms and clinical signs of patients undergoing surgery for periocular dermoid cysts, only those with radiological investigation being included in this paper. The clinical course is considered in relation to the histopathological changes.

\section{Patients and methods}

Although a large number of patients with periocular dermoids have been treated in the Orbital Service at Moorfields Eye Hospital, many (120/280 during the study period; $43 \%$ ) did not undergo radiological investigation as their management was determined by clinical signs. Clinical, histopathological and radiographic data were required for this study and, of the $160(57 \%)$ patients in whom scans were taken, adequate histological and clinical details were available for review in 124.

The case-notes were reviewed for the type and duration of presenting symptoms and the signs at the time of clinical assessment in the Orbital Clinic. Details of the surgery were recorded, especially any evidence of prior inflammation (as manifest by marked adhesions to neighbouring structures, or excessive vascularity or oedema in surrounding tissues) and any changes in the neighbouring bone.

Histopathological assessment had been previously based on a limited number of equatorial sections, stained with Haematoxylin and Eosin, and inflammation was manifest as an accumulation of chronic inflammatory cells in, or near, the wall of the dermoid cyst with, in some cases, the formation of giant cells or frank granulomata (Figure 2). These inflammatory changes were sometimes associated with intramural haemorrhage, or with macrophages containing lipid clefts and with marked deposition of

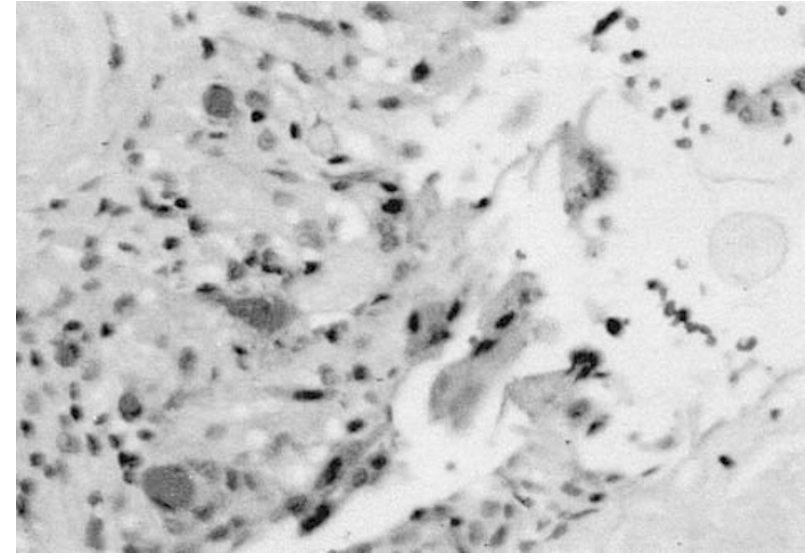

Figure 2 Moderate chronic inflammation neighbouring a dermoid cyst with disrupted epithelial surface, showing granuloma formation (Haematoxylin \& Eosin).

collagen in the surrounding tissues (Figure 3). Histologically, the inflammation was considered 'mild' where there were inflammatory cells in the cyst wall, but no fibrosis or giant cell granulomata, 'moderate' where there was some fibrosis, giant cells or granuloma formation, and 'severe' where there was a

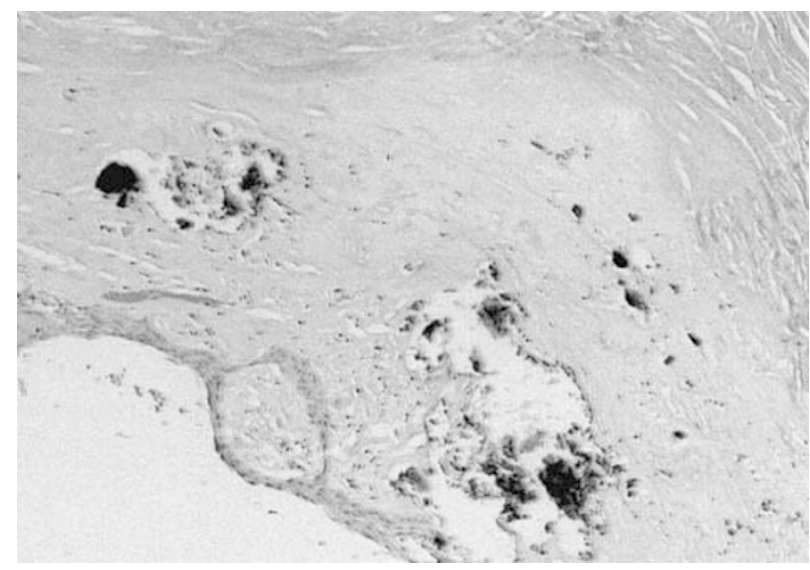

Figure 3 Severe fibrosis alongside a chronically inflamed dermoid cyst (Haematoxylin \& Eosin). 

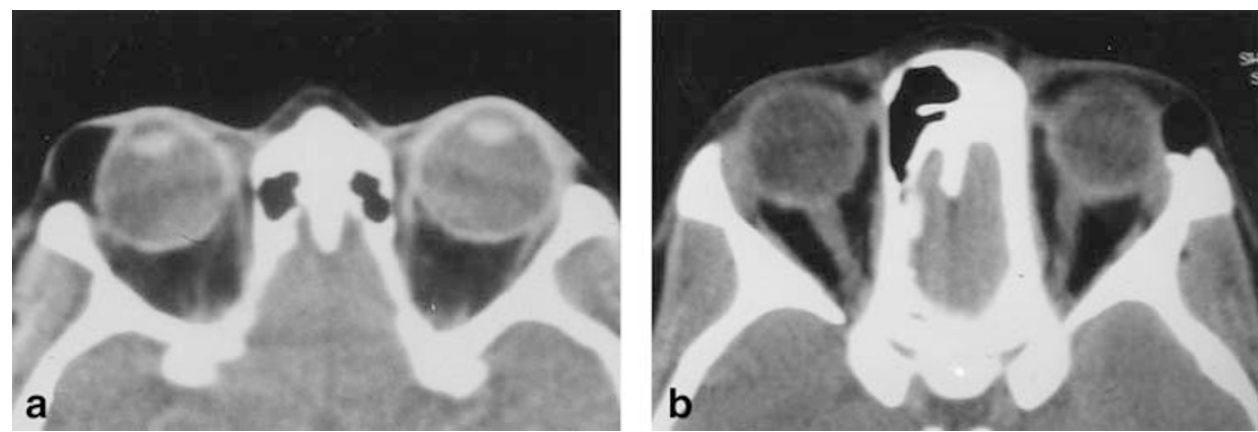

Figure 4 CT scan of two thin-walled dermoids without significant radiological signs of inflammation, one (b) being associated with a notch in the lateral orbital rim.

gross inflammatory infiltrate with, or without, significant fibrosis and granuloma formation.

One hundred and fifteen CT scans and nine MRI scans were reviewed independently (by SJC and IFM), with particular attention to the appearance and content of the dermoid cyst and any changes in the surrounding soft-tissues or orbital bone: The wall of the cyst, if visible and less than $2 \mathrm{~mm}$ thick, was regarded as 'thin' (Figure 4); the radiolucency of the cyst contents was compared with the density of normal orbital fat and the vitreous humour; changes in the surrounding bone were noted. The radiological feature considered suggestive of inflammation was the presence of soft-tissue opacities outside the cyst wall (Figure 5) and, where the amount of abnormal tissue around the cyst was greater than the size of the cyst, this was recorded as evidence of 'extensive' inflammatory disease (Figure 6). The orbital fat was also compared with that of the opposite normal side, with particular attention to the changes of diffuse inflammatory oedema or vascular congestion.

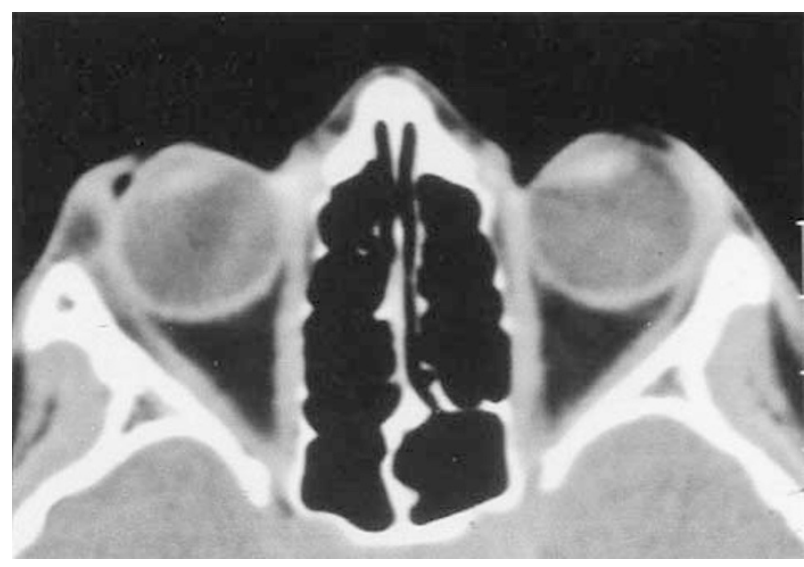

Figure 5 Dermoid cyst at the right orbital rim, associated with some neighbouring soft-tissue opacities that are compatible with moderate inflammation.

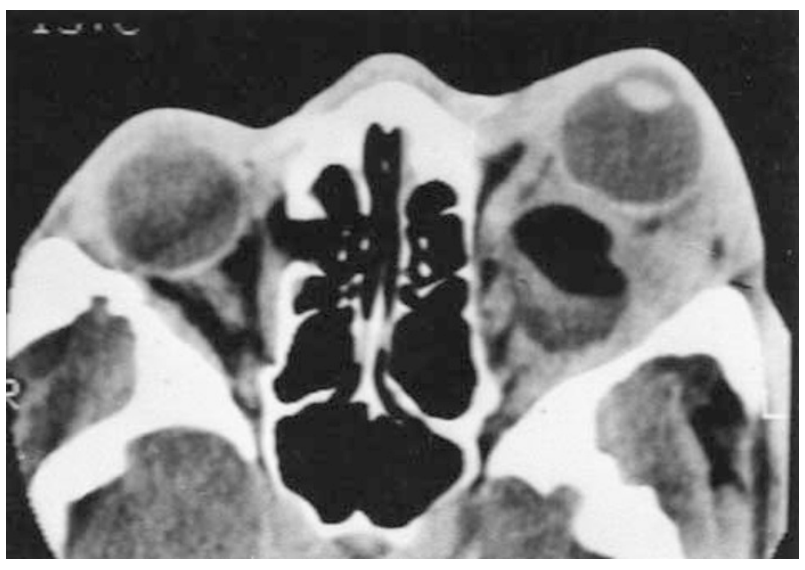

Figure 6 Left deep orbital dermoid with widespread opacification of neighbouring orbital fat, compatible with extensive inflammatory changes.

\section{Results}

One hundred and twenty-four patients (63 male, 61 female) presented with unilateral periocular dermoids, the age at presentation being from less than 1 year to 65 years (mean 18.6 years; median 11.5 years; Table 1 ).

The duration of symptoms was between 4 weeks and 30 years and in most patients the presenting symptom was a periocular lump $(77 \%)$ or fullness of the eyelid (27\%) (Table 2). In 38/124 (31\%) cases there had been, at some stage, clinical symptoms suggestive of inflammation (a painful swelling, localised redness or a marked, but variable, lid swelling) or there were signs of inflammation at initial assessment; there being histological evidence of inflammation in all 38 cases with such signs and symptoms. Inflammation had occurred from the youngest age (1 year) to the rather older patient (61 years), with a peak incidence in patients presenting in the fourth decade (Table 1).

Fifty-seven cysts $(46 \%)$ had a majority of contents with CT attenuation compatible with a high lipid content, thirty-eight (67\%) of these having attenuation 
Table 1 Clinical, radiological and histopathological evidence of inflammation in relation to dermoid cyst removal in 124 patients (percentage proportion, with $95 \%$ confidence limits, in brackets)

\begin{tabular}{|c|c|c|c|c|c|c|c|}
\hline \multirow[t]{2}{*}{ Characteristic } & \multicolumn{6}{|c|}{ Age at surgery (years) } & \multirow[t]{2}{*}{ Whole group } \\
\hline & $1-5$ & $6-10$ & $11-20$ & $21-30$ & $31-40$ & $41+$ & \\
\hline $\begin{array}{l}\text { Number of cases } \\
\text { (\% of total) }\end{array}$ & $\begin{array}{c}42 / 124 \\
(34 \%) \\
(26,42)\end{array}$ & $\begin{array}{l}14 / 124 \\
(11 \%) \\
(6,17)\end{array}$ & $\begin{array}{c}11 / 124 \\
(9 \%) \\
(4,14)\end{array}$ & $\begin{array}{l}17 / 124 \\
(14 \%) \\
(8,20)\end{array}$ & $\begin{array}{l}22 / 124 \\
(18 \%) \\
(11,24)\end{array}$ & $\begin{array}{l}18 / 124 \\
(15 \%) \\
(8,21)\end{array}$ & $\begin{array}{c}124 \\
(100 \%)\end{array}$ \\
\hline $\begin{array}{l}\text { Inflammatory signs or } \\
\text { symptoms }(* *)^{*}\end{array}$ & $\begin{array}{c}11 / 42 \\
(26 \%) \\
(13,39)\end{array}$ & $\begin{array}{l}4 / 14 \\
(29 \%) \\
(5,52)\end{array}$ & $\begin{array}{c}2 / 11 \\
(20 \%) \\
(-5,41)\end{array}$ & $\begin{array}{l}5 / 17 \\
(29 \%) \\
(8,51)\end{array}$ & $\begin{array}{c}11 / 22 \\
(50 \%) \\
(29,71)\end{array}$ & $\begin{array}{l}5 / 18 \\
(28 \%) \\
(7,48)\end{array}$ & $\begin{array}{c}38 / 124 \\
(31 \%)\end{array}$ \\
\hline $\begin{array}{l}\text { Radiological evidence of } \\
\text { inflammation }\end{array}$ & $\begin{array}{l}7 / 42 \\
(17 \%) \\
(5,28)\end{array}$ & $\begin{array}{c}2 / 14 \\
(14 \%) \\
(-4,33)\end{array}$ & $\begin{array}{c}1 / 11 \\
(9 \%) \\
(-8,26)\end{array}$ & $\begin{array}{l}4 / 17 \\
(24 \%) \\
(3,44)\end{array}$ & $\begin{array}{l}4 / 22 \\
(18 \%) \\
(2,34)\end{array}$ & $\begin{array}{l}4 / 18 \\
(22 \%) \\
(3,41)\end{array}$ & $\begin{array}{c}22 / 124 \\
(28 \%)\end{array}$ \\
\hline Calcification & - & - & - & $\begin{array}{r}2 / 17 \\
(12 \%)\end{array}$ & $\begin{array}{l}2 / 22 \\
(9 \%)\end{array}$ & $\begin{array}{r}2 / 18 \\
(11 \%)\end{array}$ & $\begin{array}{c}6 / 124 \\
(5 \%)\end{array}$ \\
\hline $\begin{array}{l}\text { Inflammation } \\
\text { around cyst }\end{array}$ & $\begin{array}{r}7 / 42 \\
(17 \%)\end{array}$ & $\begin{array}{l}1 / 14 \\
(7 \%)\end{array}$ & - & $\begin{array}{r}2 / 17 \\
(12 \%)\end{array}$ & $\begin{array}{l}1 / 22 \\
(4 \%)\end{array}$ & $\begin{array}{l}1 / 18 \\
(5 \%)\end{array}$ & $\begin{array}{l}12 / 124 \\
(10 \%)\end{array}$ \\
\hline $\begin{array}{l}\text { Extensive changes } \\
\text { around cyst }\end{array}$ & - & $\begin{array}{l}1 / 14 \\
(7 \%)\end{array}$ & $\begin{array}{l}1 / 11 \\
(9 \%)\end{array}$ & $\begin{array}{r}2 / 17 \\
(12 \%)\end{array}$ & $\begin{array}{r}3 / 22 \\
(13 \%)\end{array}$ & $\begin{array}{r}3 / 18 \\
(17 \%)\end{array}$ & $\begin{array}{c}10 / 124 \\
(8 \%)\end{array}$ \\
\hline $\begin{array}{l}\text { Histopathological } \\
\text { evidence of } \\
\text { inflammation }\end{array}$ & $\begin{array}{c}29 / 42 \\
(69 \%) \\
(55,83)\end{array}$ & $\begin{array}{c}9 / 14 \\
(64 \%) \\
(39,89)\end{array}$ & $\begin{array}{c}6 / 11 \\
(55 \%) \\
(25,84)\end{array}$ & $\begin{array}{c}13 / 17 \\
(76 \%) \\
(56,97)\end{array}$ & $\begin{array}{c}17 / 22 \\
(77 \%) \\
(60,95)\end{array}$ & $\begin{array}{c}15 / 18 \\
(83 \%) \\
(66,101)\end{array}$ & $\begin{array}{c}89 / 124 \\
(72 \%)\end{array}$ \\
\hline (None) & $13 / 42$ & $5 / 14$ & $5 / 11$ & 4/17 & $5 / 22$ & $3 / 18$ & $35 / 124$ \\
\hline Mild & $\begin{array}{r}4 / 29 \\
(14 \%)\end{array}$ & $\begin{array}{c}4 / 9 \\
(44 \%)\end{array}$ & $\begin{array}{c}2 / 6 \\
(33 \%)\end{array}$ & $\begin{array}{r}5 / 13 \\
(38 \%)\end{array}$ & $\begin{array}{r}9 / 17 \\
(53 \%)\end{array}$ & $\begin{array}{r}5 / 15 \\
(33 \%)\end{array}$ & $\begin{array}{r}29 / 89 \\
(33 \%)\end{array}$ \\
\hline Moderate & $\begin{array}{r}9 / 29 \\
(31 \%)\end{array}$ & $\begin{array}{c}2 / 9 \\
(22 \%)\end{array}$ & $\begin{array}{c}2 / 6 \\
(33 \%)\end{array}$ & $\begin{array}{r}6 / 13 \\
(47 \%)\end{array}$ & $\begin{array}{r}5 / 17 \\
(29 \%)\end{array}$ & $\begin{array}{r}8 / 15 \\
(54 \%)\end{array}$ & $\begin{array}{r}32 / 89 \\
(36 \%)\end{array}$ \\
\hline Severe & $\begin{array}{l}16 / 29 \\
(55 \%)\end{array}$ & $\begin{array}{l}3 / 9 \\
(33 \%)\end{array}$ & $\begin{array}{l}2 / 6 \\
(33 \%)\end{array}$ & $\begin{array}{r}2 / 13 \\
(15 \%)\end{array}$ & $\begin{array}{r}3 / 17 \\
(18 \%)\end{array}$ & $\begin{array}{r}2 / 15 \\
(13 \%)\end{array}$ & $\begin{array}{l}28 / 89 \\
(31 \%)\end{array}$ \\
\hline
\end{tabular}

**Symptoms and signs regarded as clinically indicative of inflammation.

the same as orbital fat. A thin capsule was visible in one-half of the 38 cysts with orbital fat density and there was no content of other density in $26(68 \%)$ of the 38 cysts. Although neighbouring bone changes were detected in 104/124 (84\%) scans, calcification within the dermoid-generally a few flecks in the wall of the cyst-was present in only nine cases (7\%); inflammation was, however, present in all tissues from dermoid cysts showing radiological calcification.

Abnormal soft-tissue density, suggestive of inflammation, was present around the dermoid cyst in $22 / 124(18 \%)$ of scans, these changes being extensive in 10/124 (8\%) patients (Figures 5 and 6; Table 1).

Surgery was performed between the ages of 1 and 66 years, generally shortly after their referral to the Orbital Clinic. All were unilateral lesions and 69/124 $(56 \%)$ were right-sided, with the majority $(63 \%)$ in the supero-temporal quadrant (Table 3 ). In $12 \%$ of cases there was fixation to bone and adherence to neighbouring structures was recorded in the surgical notes for 52/124 (42\%) cases; it remains uncertain whether these adhesions were the normal fine fibrovascular adhesions or abnormal post-inflammatory adhesions. Extraorbital extension of the dermoid cyst was present in 12/124 (10\%), with nine extending into the temporalis fossa and three into the middle or anterior cranial fossae.

All excised specimens showed a stratified squamous epithelial lining, this being keratinised in 101/124 (81\%) cases, with free keratinous debris in the cyst lumen in $91(73 \%)$ cases. In $21(17 \%)$ specimens there was a particularly thin wall (in the order of $0.3 \mathrm{~mm}$ or less) and a thick wall ( $2 \mathrm{~mm}$ or more) was demonstrated in 19 (15\%), with one or more types of cutaneous structures (such as sweat glands or pilosebaceous units) in 72 (58\%) of specimens (Table 3 ). Histological evidence of chronic inflammation, from mild to marked, was present in the most cases (89/124; $72 \%$ ), with no relationship to age (Table 1; Chi-squared test for trend, $P=0.18)$. In $48 / 124$ cases $(39 \%)$ there was an excess of fibrosis in, or around, the wall of the dermoid cyst. 
Table 2 Presenting symptoms and signs in 124 patients with periorbital dermoid cysts and 156 other patients, without imaging or adequate data, who were not included within the study

\section{Presenting symptom or Number of patients Number of patients sign within study (\%) excluded from study} (\%)

$\begin{array}{lrr}\begin{array}{l}\text { Symptoms: } \\ \text { Eyebrow/eyelid }\end{array} & 96 / 124(77 \%) & 93 / 156(60 \%) \\ \quad \text { lump } & & \\ \text { Periorbital swelling } & 43 / 124(33 \%) & 27 / 156(17 \%) \\ \text { Proptosis } & 12 / 124(9 \%) & 28 / 156(18 \%) \\ \text { Diplopia } & 13 / 124(10 \%) & 4 / 156(3 \%) \\ \text { Pain }(* *) & 19 / 124(15 \%) & 12 / 156(8 \%) \\ \text { Redness }\left(^{* *}\right) & 14 / 124(11 \%) & 3 / 156(2 \%) \\ \text { Epiphora } & 2 / 124(2 \%) & 3 / 156(2 \%)\end{array}$

Signs:

$\begin{array}{lrcc}\text { Palpable mass } & 90 / 124(73 \%) & 130 / 156(83 \%) \\ \text { Periorbital swelling } & 25 / 124(20 \%) & - \\ \text { Proptosis } & 27 / 124(22 \%) & 45 / 156(29 \%) \\ \text { Non-axial } & 11 / 124 \quad(9 \%) & 62 / 156(40 \%) \\ \quad \text { displacement } & & & \\ \text { Tenderness }(* *) & 9 / 124 & (7 \%) & - \\ \text { Skin erythema }\left(^{* *}\right) & 10 / 124 & (8 \%) & - \\ \text { Restricted ductions } & 10 / 124 & (8 \%) & 26 / 156(17 \%) \\ \text { Ptosis } & 9 / 124 & (7 \%) & -\end{array}$

**Symptoms and signs regarded as clinically indicative of inflammation.

Table 3 Surgical and histological characteristics of 124 periorbital dermoid cysts

\begin{tabular}{lr}
\hline Characteristic & $\begin{array}{c}\text { Number of } \\
\text { cases (\%) }\end{array}$ \\
\hline Location of dermoid cyst: & \\
$\quad$ Superotemporal quadrant & $78(63 \%)$ \\
Superonasal quadrant & $32(26 \%)$ \\
Inferotemporal quadrant & $5(4 \%)$ \\
Inferonasal quadrant & $5(4 \%)$ \\
Post-equatorial (deep orbital) & $4(3 \%)$ \\
Histological structures within wall of dermoid & \\
cyst: & \\
Sebaceous glands & $61(49 \%)$ \\
Sweat glands & $38(31 \%)$ \\
Hair follicles & $30(24 \%)$ \\
Goblet cells & $29(23 \%)$ \\
Giant cells or granulomas & $34(27 \%)$ \\
& \\
Histological contents of dermoid cyst: & \\
Keratin & $67(54 \%)$ \\
Sebaceous lipid & $7(6 \%)$ \\
Keratin and lipid & $24(19 \%)$ \\
Cartilage/Bone $\left.{ }^{*}\right)$ & $1+1(2 \%)$ \\
\hline
\end{tabular}

*Fragments of these tissues free within the cyst lumen are probably due to their being displaced from the wall during preparation of the histological sections.

\section{Discussion}

Most dermoid cysts contain a variable mixture of keratin or sebaceous lipid, secreted by the epithelial lining of the cyst (Table 3). The slow enlargement of dermoid cysts, due to accumulation of this debris within the lumen, probably leads to attenuation of the epithelial lining and leakage of lipids and keratin into the tissues of the cyst wall. This leakage would appear to cause an acute (Figure 1) or chronic inflammatory response with, in some cases, phagocytosis of lipid by macrophages, giant cell and granuloma formation, and secondary fibrosis around the cyst (Figures 2 and 3).

Neighbouring normal tissues are affected by inflammatory cells recruited to the area around the cyst and by the fibrosis occurring during the resolution of inflammation.

There is a selection bias for the patients in this series, due to our not scanning many $(120 / 280,43 \%$; Table 2) 'simple' cases, but the characteristics for patients included in this study were similar to those in other published series from other centres. ${ }^{2,3,5,6,8,9}$ Although presenting at various ages over seven decades, most were symptomatic in the first decade (Table 1); the majority of cysts lie superficially at the superotemporal quadrant of the orbit (Table 3) and present as a painless lump (Table 2); a squamous epithelial lining is common, with keratin formation in most cases (Table 3).

In contrast to $38 \%$ in the series by Shields, ${ }^{8}$ pathological evidence of inflammation was present in over two-thirds of our cases (Table 3), this probably being due, in part, to a selection bias for imaging (Table 2). Unlike other authors, ${ }^{8}$ the current study suggests a similar incidence of inflammation at all ages, histological evidence of inflammation being present even as early as one year of age. It is of concern that the fibrosis associated with chronic inflammation may not only impede subsequent removal of the underlying lesion, but also damage neighbouring healthy tissues with possible impairment of function.

Clinical symptoms and signs of inflammation were evident in only a minority of the $72 \%$ of patients with histological evidence of chronic inflammation, the incidence varying between 20 and 50\% (Table 1). Likewise, radiological signs suggestive of inflammation around a dermoid cyst are even less common (18\%; Table 1). Notably, histological changes of inflammation were present in all of the patients who had either clinical or radiological evidence of inflammation.

Although in most cases inflammation will be asymptomatic, this investigation would suggest that inflammation in the wall of a dermoid cyst, and in the 
surrounding tissues, starts early in childhood. Recognising the extremely low risk of complication associated with surgical excision of these lesions, we believe that the risk of post-inflammatory fibrosis involvement of neighbouring healthy structures-with possible impairment of function-warrants early removal of such periorbital dermoid cysts.

\section{References}

1 Pollard ZF, Harley RD, Calhoun J. Dermoid cysts in children. Pediatrics 1976; 57: 379-382.

2 Shields JA, Bakewell B, Augsburger JJ, Donoso LA, Bernardino V. Space-occupying orbital masses in children. A review of 250 consecutive biopsies. Ophthalmology 1986; 93: 352-364.

3 Sherman RP, Rootman J, Lapointe JS. Orbital dermoids: clinical presentation and management. Brit J Ophthalmol 1984; 68: 642-652.
4 Rootman J. Frequency and differential diagnosis of orbital disease. In: Rootman J (ed). Diseases of the Orbit. A Multidisciplinary Approach. JB Lippincott Company: Philadelphia, 1988, p 124.

5 Lane CM, Ehrlich WW, Wright JE. Orbital dermoid cyst. Eye 1987; 1: 504-511.

6 Bonavolonta G, Tranfa F, de Conciliis C, Strianese D. Dermoid cyst: 16 year survey. Ophthalmic Plast Reconstr Surg 1995; 11: 187-192.

7 Sathananthan N, Moseley If, Rose GE, Wright JE. The frequency and clinical significance of bone involvement in outer canthus dermoid cysts. Brit J Ophthalmol 1993; 77: 789-794.

8 Shields JA, Kaden IH, Eagle RC, Shields CL. Orbital dermoid cyst: clinicopathological correlation, classification and management. The 1997 Josephine Schueler Lecture. Ophthalmic Plast Reconstr Surg 1997; 13: 265-276.

9 Henderson JW, Campbell RJ, Farrow GM, Garrity JA. Orbital Tumors, 3rd edn. Raven Press: New York, 1994, pp 53-61. 